\title{
APLICACIÓN DE LAS IMÁGENES LANDSAT TM AL ESTUDIO DE LA ISLA TÉRMICA DE ZARAGOZA. PRIMEROS RESULTADOS ${ }^{1}$
}

\author{
Juan R. DE LA RIVA, José M“ CUADRAT, Fernando LÓPEZ-MARTín \\ Departamento de Geografía y Ordenación del Territorio \\ Universidad de Zaragoza
}

Alberto MARTÍ

Departamento de Geografía

Universidad de Santiago de Compostela

\begin{abstract}
Resumen: A partir de dos imágenes del sensor Thematic Mapper de Landsat se lleva a cabo un primer análisis cualitativo de la características del campo térmico de la ciudad de Zaragoza a las $10 \mathrm{~h}$ TMG, tanto en relación con su entorno inmediato como en sus variaciones internas.
\end{abstract}

Palabras clave: Isla térmica, clima urbano, Landsat TM, Zaragoza.

\begin{abstract}
A qualitative analysis of the thermic pattern caracteristics of Zaragoza is carried out by two Landsat Thenatic Mapper images (10 h GMT), both in relation with its immediate environment and its internal changes.
\end{abstract}

Key words: Thermic island, urban climate, Landsat TM, Zaragoza.

Las imágenes captadas por sensores remotos son una herramienta útil para el análisis de las modificaciones microclimáticas que la ciudad genera en su entorno, especialmente en lo relativo a la alteración de los campos térmico y de emisividad (CASELLES Y OT., 1997). La teledetección permite espacializar y cuantificar estas modificaciones debidas tanto a las variaciones en la insolación como a la presencia de focos emisores propios y a la respuesta diferencial de las cubiertas urbanas al calor. En esta línea de aplicación de las imágenes de satélite al estudio del clima urbano, iniciada en otros paises a mediados de los años setenta, destacan los trabajos desarrollados en el nuestro para las ciudades de Madrid (López-GómEZ Y OT., 1990, 1991 y 1993) y Valencia (MELIÁ Y OT., 1988; CASELLES Y OT., 1990 y en prensa).

\footnotetext{
${ }^{1}$ Este trabajo se integra en el proyecto de investigación Las condiciones climáticas del ambiente urbano de Zaragoza, Huesca y Teruel, que fue financiado por la Diputación General de Aragón.
} 


\section{BALANCE ENERGÉTICO Y MEDICIÓN REMOTA DE LA TEMPERTURA EN MEDIOS URBANOS}

La textura rugosa del medio urbano otorga a los espacios en sombra un protagonismo sólo comparable, en el medio rural, al de la vegetación arbórea densa; también de cierta importancia es la presencia de partículas contaminantes, que produce un efecto invernadero en la capa de aire en contacto con la superficie; se genera además un comportamiento peculiar y diferencial en relación con la transmisión calórica de los distintos materiales de construcción, la forma y disposición de las edificaciones. Por todo ello, el balance energético presenta en la ciudad ciertas peculiaridades (ESCOURROU, 1991) ${ }^{2}$ : la radiación global disminuye, pues el incremento de la energía difusa no compensa el descenso de la directa, y la energía infrarroja descendente aumenta por la presencia de partículas en el aire, mientras que la ascendente es muy variable en función de la naturaleza de la cubierta. De aquí la importancia de las modificaciones en el consumo energético por el sustrato urbano: a 1 a radiación neta se añade la energía antrópica, resolviéndose ambas, básicamente, en forma de calor almacenado por los edificios (por calefacciones, tráfico, metabolismo humano...), un menor peso del calor latente por la impermeabilización del suelo y un incremento del calor sensible por el calentamiento del aire en contacto con el suelo.

Nuestro análisis se va a apoyar en los valores de radiancia que el satélite registra, en relación con la emisión de las diferentes cubiertas, en el infrarrojo térmico y que son función de su temperatura. La medición de este parámetro a partir de datos de satélite presenta una serie de peculiaridades, así como de limitaciones, importantes, correctamente explicadas en CHuVreco (1996), que tan sólo vamos a apuntar. El carácter de cuerpos grises de la mayor parte de las cubiertas conduce a considerar, para el análisis preciso de su temperatura a partir de estos datos, su diversa emisioidad (E). Ésta expresa la relación entre la emitancia de cada superficie y la que tendría de ser un emisor perfecto, cuerpo negro (E=1), a la misma temperatura; indicando, cuanto más próxima a la unidad, que la cubierta absorbe y radia una proporción mayor de la energía incidente. Las tres cubiertas fundamentales de los medios urbanos presentan valores de emisividad que pueden situarse en $0^{\prime} 95$ para el asfalto, 0’93 para los edificios y 0’98 para la vegetación (CASELLES Y OT., 1990) ${ }^{3}$.

En esta primera explotación de los datos Landsat TM al análisis de la Isla térmica de Zaragoza se asumirá la simplificación de una emisividad, constante para

\footnotetext{
2 En términos generales, la radiación neta absorbida por el suelo es resultante de la energía solar visible (directa y difusa), parcialmente reenviada en forma de albedo, y del balance infrarrojo (ascendente-descendente); la infrarroja es resultado de la transformación de la visible en calor.

3 Según CURRAN (1985), a $20^{\circ}$ C la emisividad de diferentes cubiertas es, en medios rurales: 0’98 agua, $0^{\prime} 99$ vegetación cerrada, $0^{\prime} 98$ idem abierta, $0^{\prime} 95$ suelos margosos húmedos y $0^{\prime} 92$ idem secos; en la ciudad: $0^{\prime} 97$ asfalto, $0^{\prime} 96$ plástico/pintura, $0^{\prime} 93$ ladrillo, $0^{\prime} 90$ madera y $0^{\prime} 16$ acero.
} 
toda la imagen, igual a 1 . Así se procede también en los trabajos existentes, con imágenes del mismo sensor, para las ciudades de París (CANTAT, 1987) y Madrid (LÓPEZ-GÓMEZ Y OT., 1990 y 1993). En las investigaciones sobre Valencia, en cambio, sí se efectúa esta corrección, si bien con imágenes NOAA, de resolución espacial menor (V. CASELles Y OT. en Bibliografía); a partir del cálculo de la emisivad efectiva -en relación con el porcentaje de cada píxel por tipo de cubierta- estiman el valor corregido a partir de la temperatura radiativa captada por el satélite; las zonas con mayor porcentaje de cubierta vegetal (E efectiva más alta), acusan una menor corrección, mientras que los espacios con mayor proporción de asfalto y edificación, quedan más corregidos.

Cuestión añadida es la relativa a la naturaleza física de los datos registrados por el satélite; éstos hacen referencia a la temperatura radiante de los objetos y no a la registrada para el aire mediante medidas de campo; tampoco se identifican con 1 a temperatura termométrica (CHUVIECO, 1996). No obstante, tal y como señalan MELIÁ Y от. (1988), la medida térmica del satélite -promediada para todo el sistema radiante- puede ser más representativa que aquélla del aire. En cualquier caso, las características térmicas de las cubiertas y su variación espacio-temporal están determinadas, además de por la emisividad, por cuatro propiedades fundamentales (CURRAN, 1985; CHUVIECO, 1996): capacidad térmica para almacenar calor; conductividad térmica o ritmo de transferencia del calor; difusioidad térmica o ritmo de variación de la temperatura e inercia térmica o respuesta ante los cambios de temperatura. CURRAN (1985) sintetiza el comportamiento de las diversas cubiertas tipo de la siguiente forma:

\begin{tabular}{|l|c|c|c|c|}
\hline Tipo de cubierta & Capacidad T. & Conductividad T. & Difusividad T. & Inercia T. \\
\hline VEGETACIÓN & medio-alta & baja & alta & alta \\
SUELO SECO & medio-baja & medio-baja & medio-baja & medio-baja \\
SUELO HÚMEDO & medio-baja & medio-baja & medio-baja & alta \\
AGUA & alta & baja & alta & alta \\
ÁREAS URBANAS & medio-baja & medio-alta & baja & medio-alta \\
\hline
\end{tabular}

\section{IMÁGENES UTILIZADAS Y PRETRATAMIENTOS APLICADOS}

Los datos de teledetección disponibles para el estudio de la Isla térmica obligan a decantarse bien por las imágenes diurnas de buena resolución espacial, bien por las que-diurnas o nocturnas- aportan los satélites meteorológicos. Éstas, aunque con una mejor resolución espectral, son inadecuadas para estudios microclimáticos por su resolución espacial kilométrica (vgr., $5 \mathrm{~km}$ en el térmico de Meteosat). Sólo los datos del sensor AVHRR-NOAA -con resolución al nadir de 1'1 km-son utilizables, en ciertos 
casos, a escala urbana; no obstante, las dimensiones de la ciudad de Zaragoza, que queda inscrita en un cuadrilátero de $7 \times 7 \mathrm{~km}$, aconsejaron el empleo de datos Landsat TM con el objeto de no limitar en exceso el análisis de su elevada heterogeneidad interna.

El sensor TM registra, en sus bandas 1 a 5 y 7 , la energía reflejada por 1 a superficie terrestre y, en la banda 6, la emitida en función de la temperatura del objeto detectado. Estas imágenes presentan una resolución espacial de $120 \mathrm{~m}$ en el térmico y por su hora de paso, en torno a las $10 \mathrm{~h} \mathrm{TMG}$, permiten analizar el comportamiento térmico de la ciudad en el intervalo entre el amanecer y el mediodía. Esta última característica resulta interesante por cuanto, gracias al trabajo de campo, se tiene ya un conocimiento preciso de la Isla de calor nocturna en Zaragoza (CUADRAT Y OT., 1994). Con el objeto de analizar el fenómeno en diferentes momentos del año, se procedió a la adquisición de datos para tres fechas diversas, de las que se presentan los resultados obtenidos para el 20 de abril y el 25 de julio, ambas de 1992. La selección de las imágenes requirió el análisis de la situación meteorológica, favorable en términos de estabilidad para las fechas seleccionadas. El tratamiento se realizó con los programas Erdas-VGA 7.5 e Ilwis 1.3.

El canal 6, utilizado en este trabajo, es sensible a la radiación emitida entre $10^{\prime} 4$ y 12'5 $\mu \mathrm{m}$. Los valores registrados -niveles de radiancia- que constituyen la muestra radiométrica de la escena se codifican en Niveles Digitales (ND), entre 0 y 255; sin embargo, el rango representado de forma significativa es normalmente menor: entre los ND 120-139 para la imagen de abril y entre 135-156 para la de julio. Pese a que la distribución es normal en ambos casos (con ND medios 129 y 146, respectivamente), los datos denotan una dispersión no muy elevada -desviación estándar 6’5 y $7^{\prime} 4$, respectivamente- que, aunque considerablemente inferior a la de las restantes bandas, manifiesta un grado de heterogeneidad habitual en ésta.

Un primer pretratamiento estuvo orientado a corregir el efecto de bandeado (striping) resultante del desajuste en la calibración de los detectores que componen el sistema sensor, especialmente importante en la banda térmica por cuanto el rango digital es menor. Seguidamente se procedió a la georreferenciación de los datos, condición ineludible del análisis multiestacional y de la integración de otra información auxiliar. Una corrección geométrica afinada es además imprescindible en medios de acusada heterogeneidad espacial como el urbano y cuando la proporción de píxeles de ocupación mixta es alta como consecuencia de una resolución espacial. mediana y una reducida dimensión -en comparación con aquélla- de los objetos detectados. Se utilizaron 25 puntos de control, aceptándose un error cuadrático medio inferior a 1 pixel, trabajando sobre las bandas reflectivas de la imagen $(30 \mathrm{~m})$; el criterio de asignación fue la interpolación bilineal, con el objeto de no alterar sustancialmente los ND originales y mantener una cierta calidad en la visualización. 


\section{ANÁLISIS DE LAS IMÁGENES}

Para este análisis se va a proceder mediante una doble escala de trabajo: un territorio cuadrangular de $21 \mathrm{~km}$ con centro en el núcleo urbano (Fig. 3) y otro, de más detalle, que se apoya en una ventana de $12 \mathrm{~km}$ de lado (Figs. 4 y 5). Fn aproximación sucesiva a la ciudad desde su entorno, los mapas térmicos presentados están acompañados por dos documentos de referencia: un croquis de situación con los grandes trazos urbanos (Fig. 1) y la banda 4 (infrarrojo próximo en Landsat TM, Fig. 2) ${ }^{4}$ de 1 a zona cartografiada en las Figuras 4 y 5. La cartografía térmica -banda 6- se presenta en forma de mapas raster a los que se ha aplicado una paleta de grises. Ante 1 a dificultad y complejidad que entraña la lectura de estas imágenes en su forma original, consecuencia de su carácter de muestra promedida para superficies de $120 \mathrm{~m}$ de lado, se ha procedido, tras diversos ensayos, a la aplicación de filtros lineales de suavizado sobre una ventana de $5 \times 5$ píxeles, obteniéndose las Figuras 4 y 5 ; la Figura 3 , en cambio, representa los ND de la imagen original de abril. Dado el el carácter cualitativo de nuestro análisis y la ausencia de corrección de emisividad, el empleo en las siguientes páginas de términos como frío o cálido debe entenderse como una simplificación que refiere a ND -niveles de emisión- menores o mayores.

\section{El conjunto urbano en su entorno}

La Figura 3 aporta una primera aproximarión a las modificaciones del mapa térmico del entorno de Zaragoza. A diferencia de otras ciudades como Madrid (LópEzGÓMEZ Y OT., 1990), en las que el contraste campo-ciudad es acusado y se manifiesta a esta hora de la mañana en forma de Isla de frío, el peculiar emplazamiento de Zaragoza, mayoritariamente sobre la vega del Ebro que atraviesa un paisaje semiárido de secano, hace más complejo el análisis. En términos generales es perceptible una diferenciación clara entre las huertas, más frías, y los sectores vecinos, algo más elevados y ocupados en unos casos por cultivos de secano, o sólo eventualmente regados, y en otros por un matorral poco denso que con frecuencia da paso a la roca desnuda y sólo de forma puntual a la repoblación forestal. Los sectores desprovistos de vegetación u ocupados por secanos presentan en conjunto altos ND, superiores a 133; frente a ellos se diferencian con nitidez las huertas del Ebro y de los ríos Gállego, en la margen izquierda, y Huerva, en la derecha, con ND menores de 130.

\footnotetext{
4 En esta imagen, el nivel de gris refleja la intensidad de la señal captada por el sensor, codificada en el ND, menor en el caso de tonos oscuros, que indican una reflectividad reducida en esa porción del espectro electromagnético. El agua se diferencia con nitidez en los tonos más oscuros, mientras que gran parte de los cultivos -especialmente los irrigados- aparecen con tonos claros, quedando entre ambos la vegetación arbórea (mayoritariamente de coníferas), el espacio urbanizado (tendente a uno u otro extremo en función de la densidad edificatoria y la presencia de zona verde, pero globalmente más oscuro) y los grandes ejes de comunicación.
} 
Figura 1: CROQUIS DE SITUACIÓN

ZARAGOZA Y SU ENTORNO

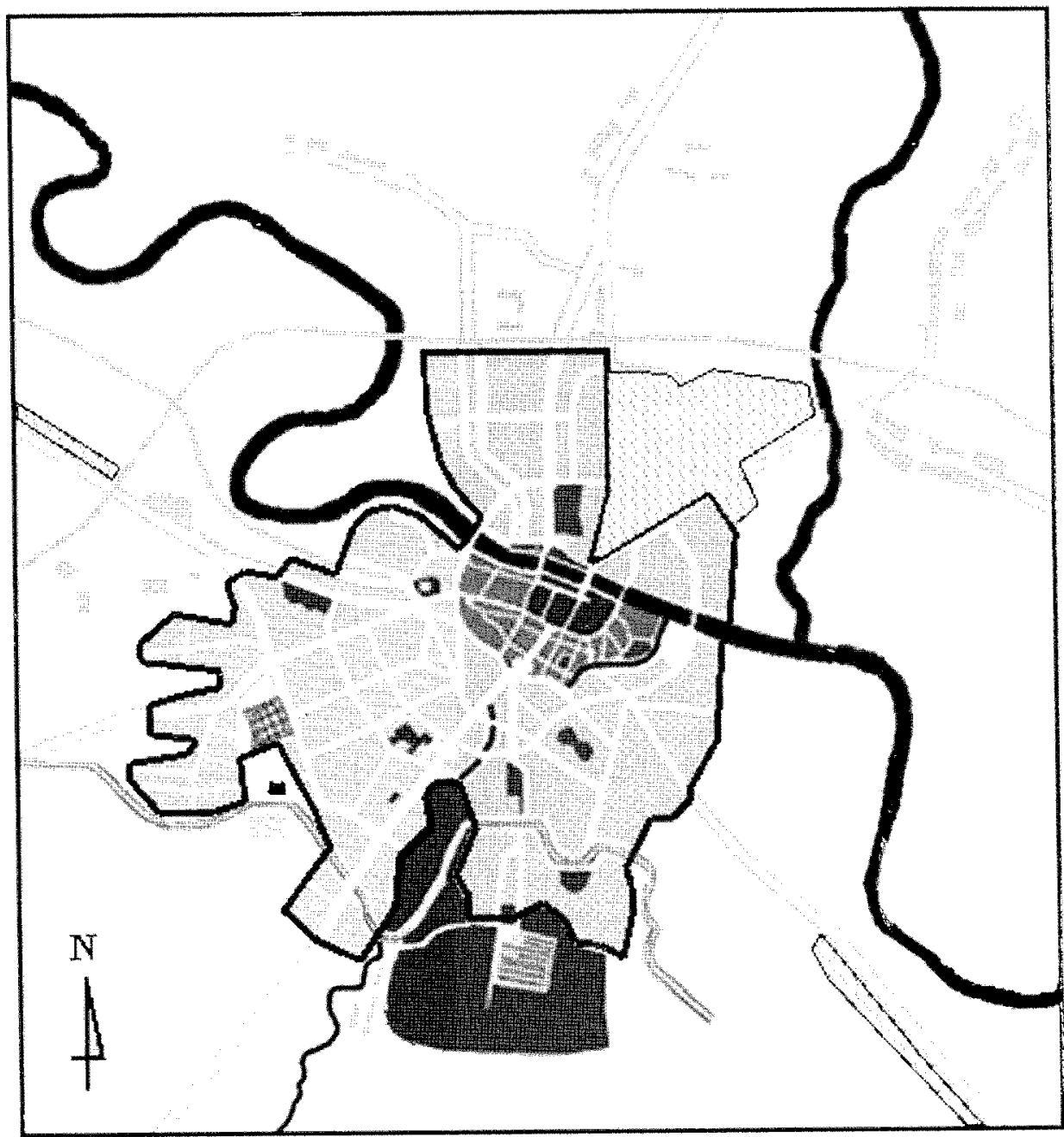

Casco romano(oscuro)

Ciudad hasta $\mathrm{XIX}$ (claro)

TResto del núdeo urbano Cursos fluviales

Princtiales vias de comunicacton

Canal Imperial

Zonas verdes

$\square$ Zonas industriales

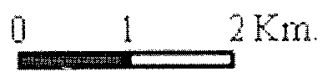


Figura 2: ZARAGOZA Y SU ENTORNO. Banda 4 (infr. próximo) Imagen Landsat TM del 25 de julio de 1992
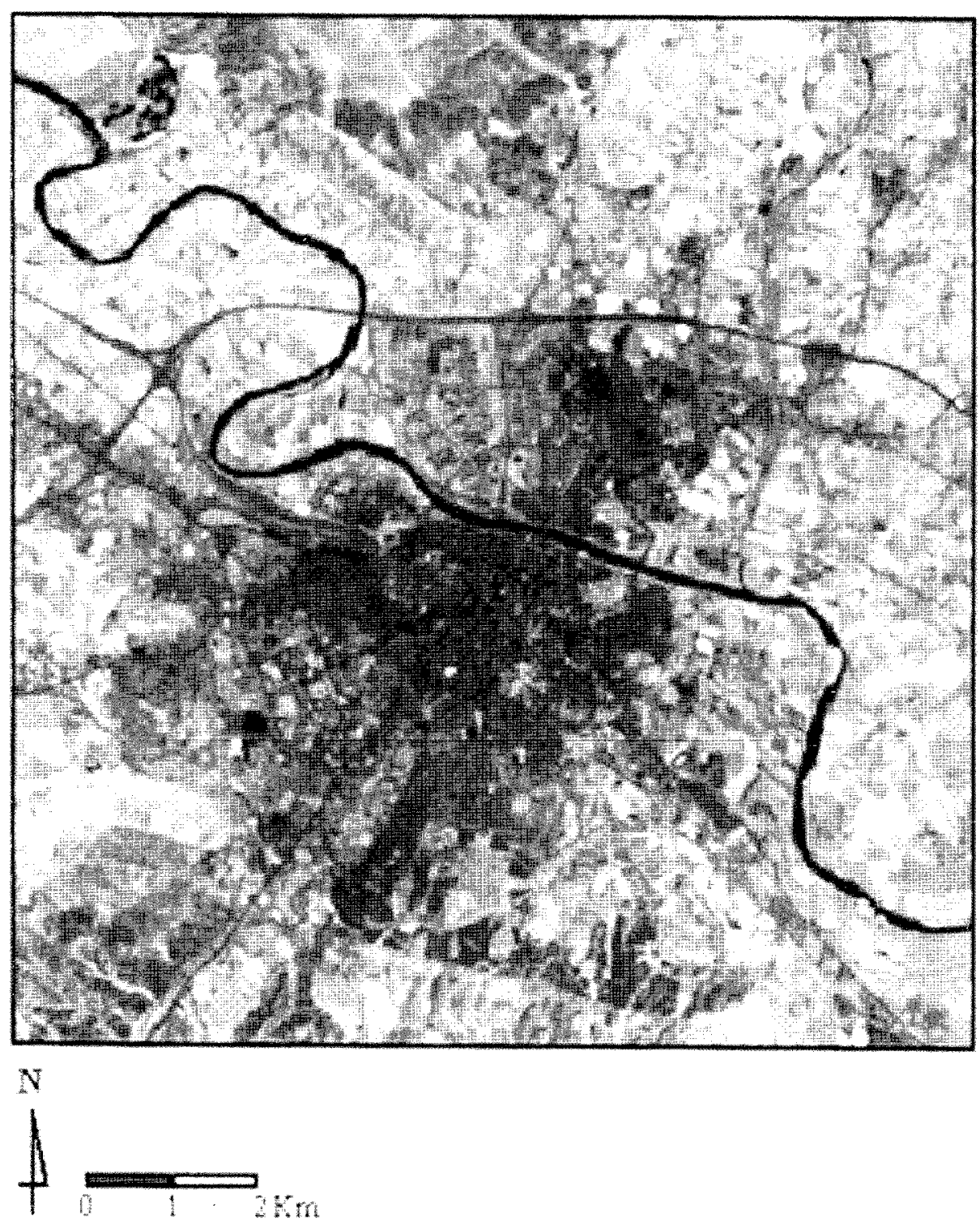
Sin embargo, a pesar del contraste dominante entre secano y regadío, la presencia del conjunto urbano es evidente. Éste se manifiesta de forma directa en la modificación del campo de temperaturas, en el sentido de un descenso de las mismas en comparación con las tierras de secano y los improductivos. De este modo, el espacio urbanizado aparece cartografiado con grises medio-oscuros (ND entre 126 y 132); de no existir los tres corredores fluviales señalados, la existencia de la Isla de frío matutina sería evidente. Este diverso comportamiento es consecuencia, fundamentalmente, de las diferencias en la insolación, relacionadas con las características texturales de unos y otros espacios; a la fuerte rugosidad del medio urbano se añade la incidencia oblicua de la radiación solar para conceder una importante significación a los espacios en sombra. Por el contrario, la mayor planitud del espacio cultivado facilita una exposición temprana y completa a la radiación solar. No es éste, por supuesto, el único factor explicativo, pues las caracteristicas diferenciales de los materiales, expresadas en las propiedades térmicas, justifican el contraste entre el regadío y el secano-matorral-roca desnuda en función, sobre todo, del contenido de agua y de la mayor o menor actividad vegetal 5 .

La urbanización se hace patente también, de modo indirecto, a través de focos y superficies o corredores térmicos de carácter cálido que se asocian a infraestructuras e instalaciones industriales. Ello se relaciona en ocasiones con sus características texturales, como en el caso de las vías de comunicación, y otras veces con la propia emisión de calor, como en los complejos industriales. En este sentido se definen con claridad dos ejes perpendiculares entre sí: el formado por las carreteras de Huesca y Valencia (dirección NNE-SSO) y el más importante de la autovía de Logroño y la carretera de Castellón (ONO-ESE); en este último se acusa además, en mayor medida que en el primero, la presencia de la industria. Esta última es también particularmente evidente en el caso de los Polígonos de Cogullada y Malpica.

Comportamientos excepcionales -algo más fríos- en el interior del espacio más caliente que rodea la ciudad son debidos a la existencia de masas arboladas más o menos densas, como en el caso del monte de San Cristóbal en Peñaflor (extremo NE, donde se suma también una exposición umbrosa) o la repoblación de Valdetalaya en Villamayor (sector centro-este, al sur de la anterior); en ambos casos, las temperaturas se sitúan en niveles semejantes a los que encontramos en la ciudad. En la imagen se constata también la existencia de una gran urbanización de planta rectangular en la margen derecha del Gállego (El Zorongo), patente en la reducción de las temperaturas como consecuencia de la presencia del riego y de elementos vegetales y de la mayor rugosidad que éstos y las edificaciones generan (más cálido el sector central, que alberga servicios comunes como aparcamientos, pistas de deporte, etc.); se perciben

\footnotetext{
5 Con independencia de que también pueda desempeñar un cierto papel la mayor rugosidad del regadío y la presencia de sombras por la vegetación intercalada de mayor porte.
} 
Figura 3: MAPA TÉRMICO DEL ENTORNO DE ZARAGOZA (20 de abril de 1992)

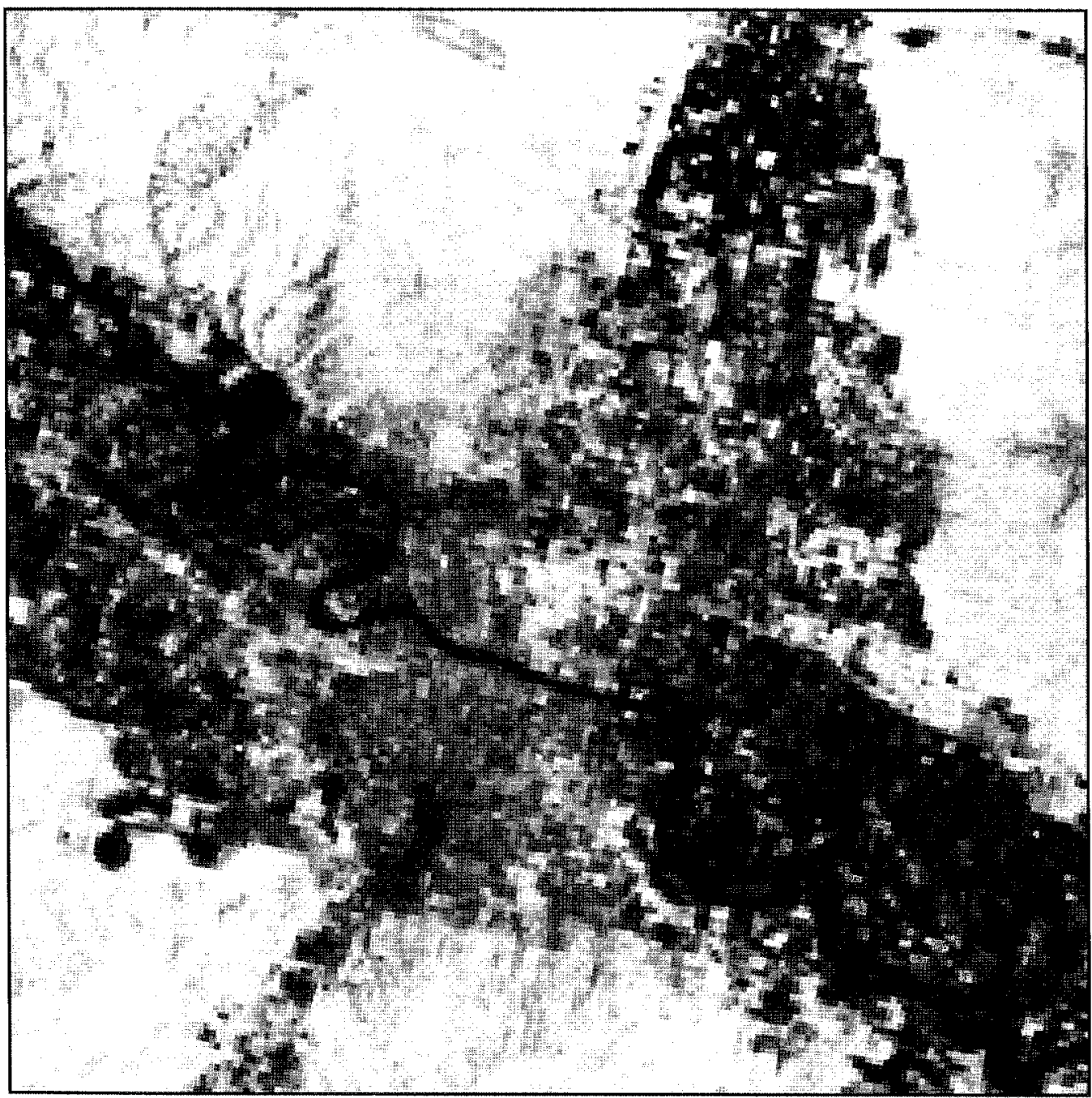

\begin{tabular}{|c|c|c|c|c|}
\hline $\begin{array}{l}<118 \\
118-123 \\
124-125\end{array}$ & $\begin{array}{l}126-127 \\
128 \\
129\end{array}$ & 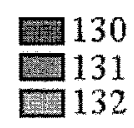 & $\begin{array}{l}\square 133 \\
\square 134 \\
\square 135-136\end{array}$ & $\begin{array}{l}\square 137-138 \\
\square 139-141 \\
\square>141\end{array}$ \\
\hline
\end{tabular}


también dos grandes pioots de riego en el cuadrante SO, con ND inferiores a los del secano entornante.

Las diferencias entre la situación abril y la de julio no son importantes si se consideran a esta escala y en términos relativos. Ciertamente, el patrón espacial sería semejante (como constataremos en las Figuras 4 y 5), si bien con una diferencia cuantitativa, prácticamente lineal, de $18 \mathrm{ND}$, superior en julio; la explicación estriba en el mayor número de horas de insolación y la menor oblicuidad de los rayos solares en el momento de captura de esta última. Al margen de esta diferencia cuantitativa, las discrepancias entre abril y julio son exiguas y se relacionan, en términos generales, con la fenología de los cultivos y los cambios en la ocupación del suelo ${ }^{6}$.

Aun no habiendo realizado la corrección de emisividad a los datos, se puede inferir con cierta seguridad su consecuencia en las imágenes. Las superficies de agua y los espacios cubiertos por vegetación densa, próximos en su comportamiento a un cuerpo negro, tan apenas se verían modificados, permaneciendo con los valores más bajos. Un ligero aumento se constataría en las tierras de la llanura aluvial, ocupadas por cultivos y suelos húmedos, distanciándose algo más de las anteriores cubiertas. E1 tejido urbano quedaría más corregido, dada la menor emisividad de asfalto y edificios, tendiendo por ello a diferenciarse más -con temperaturas más altas- de los espacios irrigados de su entorno. En cualquier caso, serían los espacios con ND más altos -suelos desnudos, industriales o desprovistos de vegetación en el campo- los más fuertemente corregidos, incrementando su temperatura en mayor proporción. En consecuencia, la presencia de la ciudad se evidenciaría todavía más, acentuándose su carácter de enclave más templado que el espacio irrigado de la llanura de inundación y los sectores arbolados, pero más frío que los secanos, pastizales e improductivos del entorno.

Son, por tanto, las cubiertas con baja conductividad térmica pero alta difusividad y, sobre todo, inercia las que manifiestan temperaturas más bajas en estas primeras horas de insolación directa. En cambio, las áreas urbanas hacen patente su mayor conductividad térmica $y$, especialmente, una inercia térmica algo menor (medio-alta), para presentar una temperatura algo más alta que el agua y la vegetación a pesar de una menor difusividad. Los cultivos y suelos más secos (secanos herbáceos, pastizales y suelos desnudos) responden, en cambio, de forma más rápida a la insolación diurna, gracias a una difusividad no tan baja como la propia de la

\footnotetext{
${ }^{6}$ Atendiendo a la peculiaridad del balance energético en el espacio urbano y al consumo de energía por el sustrato, hay que señalar el peso diferencial -según el momento dél año- de los dos términos característicos de estos medios: el calor antrópico y el almacenado por las edificaciones. Aquél será mayor en invierno mientras este último es más intenso en verano; las diferencias se deberán a las peculiaridades del tejido urbano en morfología y funcionalidad y a la presencia de vegetación, que en los meses cálidos se convierte en importante masa transpiratoria.
} 
edificación y, sobre todo, a una inercia térmica que es la menor de las que caracterizan las diferentes cubiertas presentes en las imágenes.

\section{Diferencias térmicas en el espacio urbano}

Las Figuras 4 y 5 complementan a la Figura 3 en el análisis de las diferencias térmicas dentro del espacio urbano. Considerando la situación de abril es posible distinguir:

- Sectores cálidos (ND >133). Corresponden grosso modo a las zonas industriales y espacios no edificados, infraestructuras de comunicación; cultivos de secano y vegetación natural seca (matorral y pastizal).

- Sectores medio-cálidos (ND de 133 a 131). Además de completar los espacios anteriores, estos ND se hacen ya claramente presentes en el territorio edificado.

- Sectores medio-fríos (ND de 128 a 130). Prácticamente incluyen el resto del espacio urbanizado, así como alguna zona verde urbana y cultivos de regadío.

- Sectores fríos, con ND <128. Se asocian a enclaves puntuales dentro de los sectores urbanizados y, especialmente, a las zonas arboladas, el agua y el regadío.

Las zonas más cálidas, con ND >138 (segregadas en la Figura 3), incluyen los polígonos industriales de mayores dimensiones: se diferencian con claridad Cogullada (al $\mathrm{N}$ de la ciudad) y Montemolín (Ctra. de Castellón); con los mismos ND aparecen los secanos y eriales de Valdespartera al SO y ciertos sectores de los montes de Torrero al S. Dentro del perímetro edificado tan sólo se detectan estos valores, puntualmente, en la estación ferroviaria de mercancías (al O) y en algunos solares no edificados de grandes dimensiones ${ }^{7}$. Los píxeles con ND entre 137 y 138 completan prácticamente el polígono industrial de Cogullada y el sector de Valdespartera, haciéndose más presentes en el monte de Torrero y en el Castellar; de forma puntual aparecen también en las amplias superficies no edificadas de la periferia urbana actualmente abandonadas por la actividad agrícola, como en el entorno de los barrios de Casablanca, Valdefierro y Oliver ( $O$ de la ciudad), o en el eje de salida hacia 1 a carretera de Castellón (C. Miguel Servet, al SE) ${ }^{8}$. En tomo a los anteriores se localizan los píxeles entre 134 y 136.

La separación entre las zonas anteriores y el conjunto edificado habitado se puede establecer de una forma bastante clara a expensas del ND 133; salvo

\footnotetext{
7 Los ND máximos, superiores a 141, se localizan en Cogullada -en torno a la fundición Rico \& Echeverría- y en los sectores más llanos y expuestos de Valdespartera.

${ }^{8}$ Dado el carácter aislado de estos píxeles, no aparecen en la Figura 4, filtrada, pero sí en la 3.
} 
Figura 4: MAPA TÉRMICO DE ZARAGOZA Y SU ENTORNO (20 de abril de 1992)

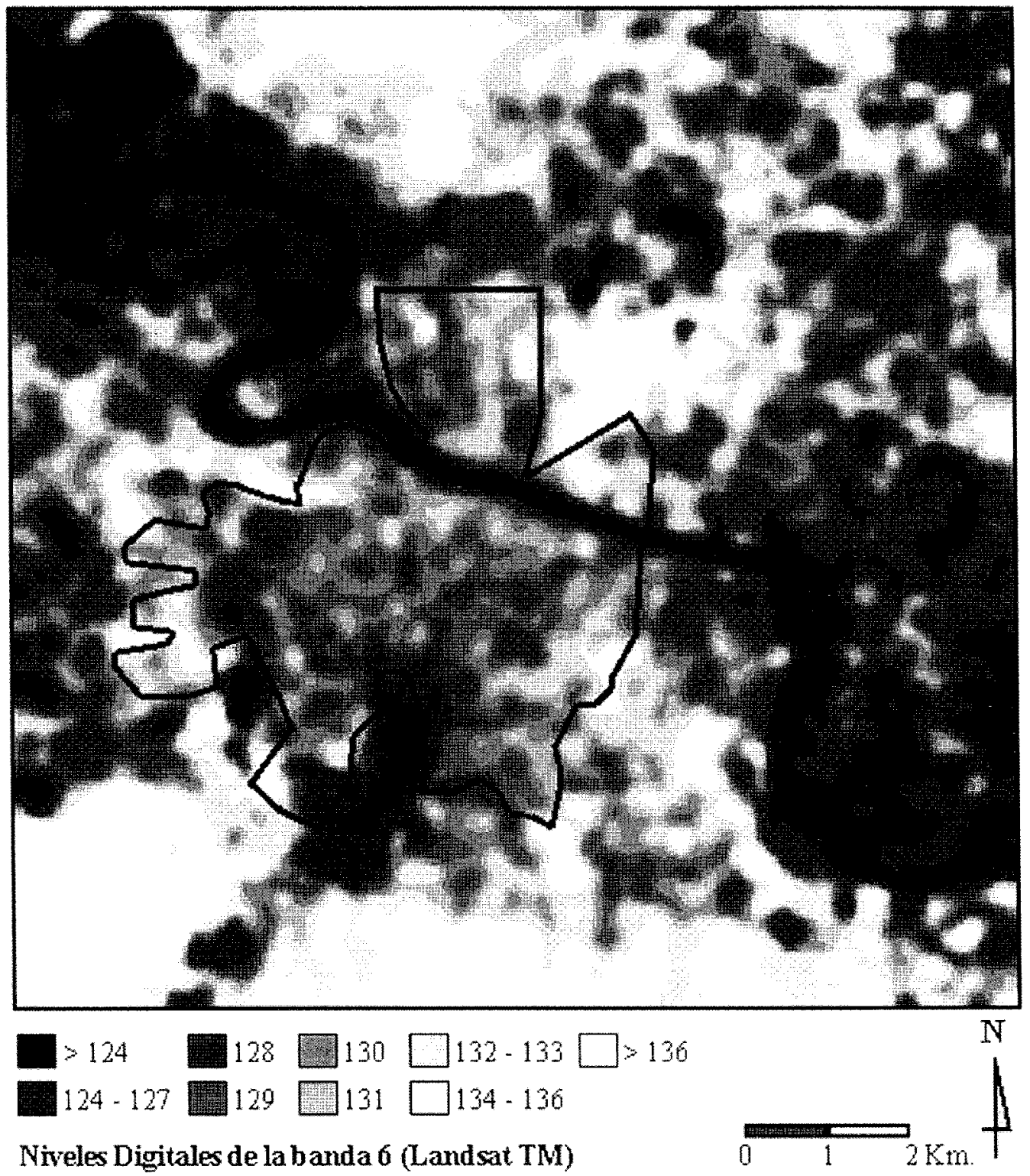


excepciones puntuales, éste es el valor más bajo que encontramos en el entorno de secano de la ciudad. También está presente en el interior del perímetro urbano, asociado a los grandes ejes de comunicación que conectan con importantes viales (Ctra Castellón/C. Miguel Servet, Ctra. Huesca/Avda. Pirineos, etc.), así como en la penetración del eje ferroviario por el O hasta la estación de El Portillo. Amplios solares vacíos dentro de la ciudad son patentes igualmente por este ND, incluso en el propio sector centro.

Los ND 131 y 132 delimitan los sectores edificados más cálidos. Una mancha bastante continua ocupa la mayor parte del casco antiguo de la ciudad romana; al $O$, separado del anterior por la Avda. Cesar Augusto, el barrio antiguo de San Pablo, presenta estos mismos valores. En el resto de la ciudad aparecerán ya de forma más aislada, aunque muy significativa, en enclaves dispersos y con más relevancia en barrios populosos como Delicias y las Fuentes. Una porción importante de estos dos últimos se encuentra con ND 130, del mismo modo que otros sectores como Hernán Cortés, el Ensanche de la Huerta de Santa Engracia, Torrero, Casablanca y parte del suelo edificado del ACTUR (margen izquierda). El resto de las zonas de edificación más densa presentan mayoritariamente ND 129.

Además de los cultivos de regadío del entorno, los ND 126 a 128 delinean los grandes ejes viarios urbanos; entre éstos destaca sobremanera el que se introduce en el interior de la ciudad con dirección SSO-NNE (C. Alférez Provisional y Gran Vía), hasta desdoblarse en el centro (plaza de Paraiso, lugar caracterizado por el fuerte viento) en dos ramales: uno que continua la misma trayectoria (calles Independencia y Coso), otro que sigue el cauce cubierto del río Huerva (paseos Constitución y La Mina). Ello constituye, sin duda, una importante vía de penetración de frío en la ciudad desde el Parque Primo de Rivera, al sur, a expensas del redireccionamiento del viento dominante del NO que encuentra un obstáculo orográfico de cierta entidad en la margen derecha de la Huerva, topográficamente más abrupta que la opuesta. Otros sectores presentan también estos mismos valores, especialmente zonas de edificación abierta como gran parte del ACTUR (en el extremo $\mathrm{N}$ de la ciudad), el cinturón que circunda la ciudad por el SO (Vía Hispanidad), la Ciudad Universitaria, el Polígono Universidad, el barrio de Casablanca, el entorno del Parque Miraflores, etc.

Con ND 118 a 125 se identifican, junto a los campos de cultivo más húmedos y los píxeles mixtos con el cauce del Ebro, los parques urbanos. Se percibe con claridad no sólo el Parque Primo de Rivera, y su prolongación al sur por el Cabezo de Buena Vista, sino también los de Palomar (al O), Tío Jorge (en la margen izquierda del Ebro) y otros de menor extensión como los de Pignatelli, Miraflores y Bruil, en el interior de la ciudad. Con estos mismos valores aparecen también diversas zonas de edificación de baja altura con importante proporción de zona verde (Ruiseñores y Paseo de Colón al S, Parque Hispanidad, al O). Las zonas de valores mínimos denotan la existencia de láminas de agua, tanto en relación con el río Ebro, sus riberas y zonas húmedas 
Figura 5: MAPA TÉRMICO DE ZARAGOZA Y SU ENTORNO (25 de julio de 1992)

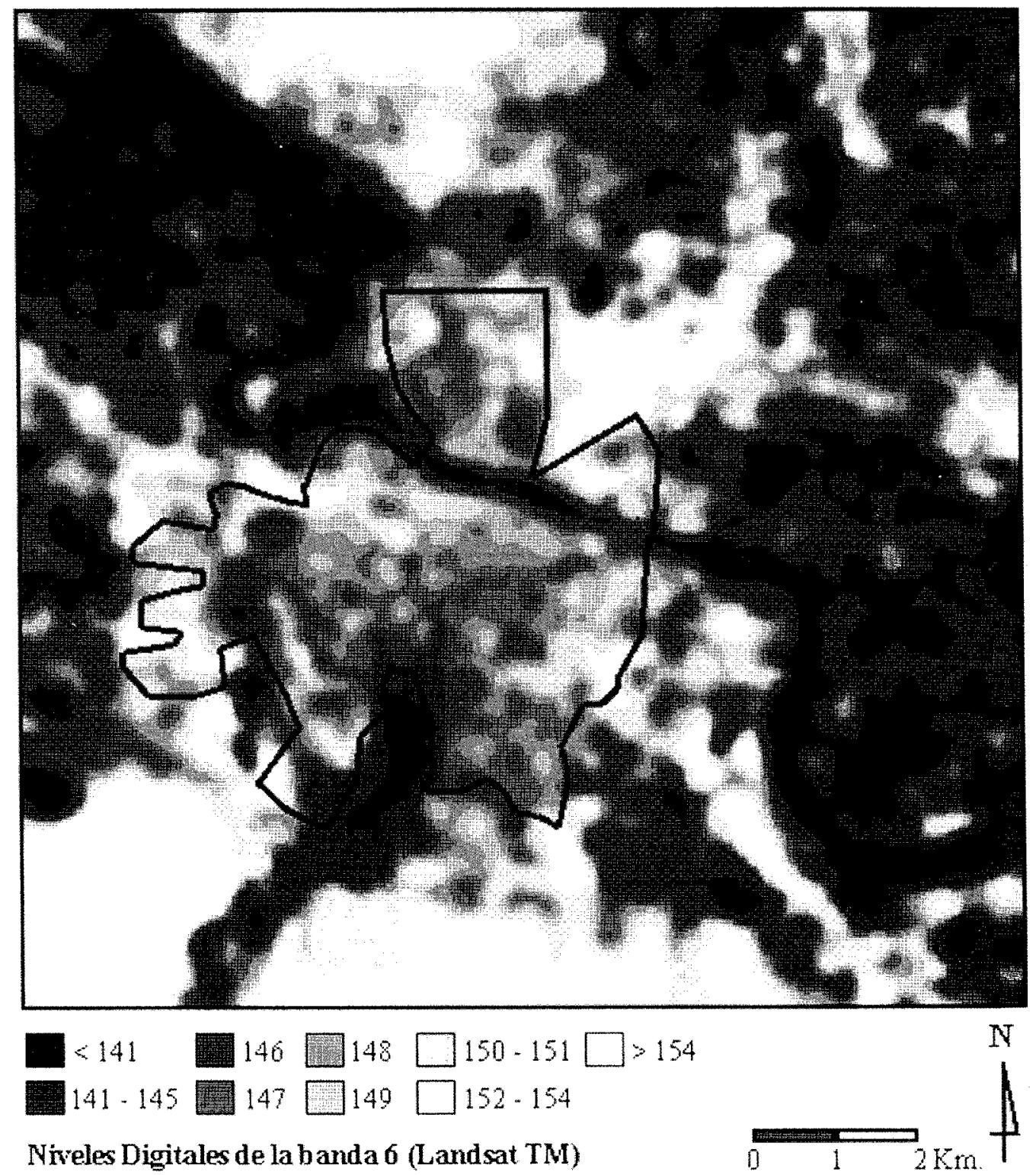


(especialmente, el Galacho de Juslibol, un meandro abandonado en el extremo NO), como en el caso de los depósitos de agua situados al SO del perímetro urbano.

La Figura 5, referida a la situación del 25 de julio, confirma el esquema espacial comentado para la Figura 4, estableciéndose tan sólo ligeras modificaciones, por supuesto al margen de la diferencia cuantitativa apuntada por la mayor radiación.

\section{CONCLUSIONES}

El empleo de las imágenes diurnas Landsat TM abordado en el presente trabajo supone una primera aproximación, desde luego no exenta de problemas, al análisis del comportamiento térmico de Zaragoza y su entorno. A las $10 \mathrm{~h}$ TMG, momento de captura de los datos, la Isla de calor nocturna, evidenciada en trabajos anteriores a partir de mediciones de campo (CUADRAT Y OT., 1994), está ya desdibujada. La ciudad tan apenas ha iniciado su proceso diario de calentamiento que revertirá, en virtud de la inercia térmica y la emisión propia de calor, en el citado fenómeno nocturno. A primera hora de la mañana, los factores que explican el esquema térmico observado están en relación, básicamente, con el diferente comportamiento de las diversas cubiertas en función de sus propiedades -especialmente la inercia térmica- y de su iluminación diferencial en relación con la rugosidad de la superficie.

A diferencia de los resultados de otros trabajos semejantes, como los señalados para París y Madrid, no puede hablarse en Zaragoza, en sentido estricto, de Isla de frío matutina. Las peculiares características de su emplazamiento y su expansión a partir de la antigua ciudad situada sobre la huerta del Ebro, en la confluencia con los ríos Gállego y Huerva, explican que aquélla se desdibuje, si bien el contraste térmico con los secanos circundantes, más cálidos, es evidente. Por otra parte, el espacio urbanizado presenta en su interior comportamientos diferentes en función de su morfología, densidad, altura de la edificación, materiales, presencia de vegetación, etc. El trabajo realizado ha permitido una aproximación cualitativa al fenómeno, que será completada mediante la conversión de los ND a medidas de temperatura mediante la corrección de emisividad en función de la ocupación del suelo.

\section{BIBLIOGRAFÍA}

CANTAT, O. (1987): Télédétection spatiale et microclimats (le cas de la region d'tle de France), IAURIF, Paris. 
CASELLES, V., LÓPEZ-GARCÍA, M.J., MELIÁ, J., PEREZ-CUEVA, A.J. (en prensa): "Analysis of the Heat-Island Effect of the City of Valencia, Spain, Trough Air Temperature Transects and NOAA Satellite Data", Theoretical Applay Climatology.

CASELLES, V., LÓPEZ-GARCÍA, M.J., MELIÁ, J., PÉREZ-CUEVA, A.J. (1990): "El efecto de isla térmica de la ciudad de Valencia obtenido a partir de transectos e imágenes NOAA-AVHRR", en III Rennión Científica del Grupo de Trabajo en Teledetección, I.T.G.E., 259-269, Madrid.

CASELlES, V., COLL, C., RUBIO, E., SOSPEDRA, F, VALOR, E., MICÓ, E. (1997): "La medida de la temperatura y de la emisividad desde satélites: estado actual y perspectivas futuras", en Casanova, J.L. y Sanz, J. (Edit.): Teledetección. Usos y aplicaciones, 487-492, Universidad de Valladolid, Valladolid.

CASElles, V., COLL, C., VALOR, E, RUBIO, E., (1995): "Mapping land surface emmissivity using AVHRR data. Application to La Mancha, Spain)", Remote Sensing Reviezus (12), 311333.

CHUVIECO, E. (1996): Fundamentos de teledetección espacial, Rialp, Madrid.

CUADRAT, J.M., DE LA RIVA, J.R., LÓPEZ, F., MARTÍ, A. (1994): "El medio ambiente urbano en Zaragoza. Observaciones sobre la isla de calor", Anales de Geografía de la Universidad Complutense (13), 127-138.

CURRAN, P.J. (1985): Principles of Remote Sensing, Longman Group Limited, London.

ESCOURROU, G. (1991): Le climat et la ville, Col. “Géographie d'aujourd'hui”, Nathan Université, París.

LOPEZ-GÓMEZ, A., LÓPEZ-GÓMEZ, J., FERNÁNDEZ-GARCÍA, F., ARROYO, F. (1991): El clima urbano de Madrid: la isla de calor, C.S.I.C., Madrid.

LÓPEZ-GÓMEZ, A., MORENO, A., FERNÁNDEZ-GARCÍA, F., PALOU, F. (1990): "La temperatura diurna en la aglomeración de Madrid mediante imágenes remotas", Estudios Geográficos (LI, 201), 705-732.

LÓPEZ-GÓMEZ, A. (Coord.), FERNÁNDEZ-GARCÍA, F., ARROYO, F., MARTín VIDE, J., CUADRAT, J.M. (1993): El clima de las ciuddades españolas, Cátedra, Madrid.

MELIÁ, J., CASELLES, V., LÓPEZ-GARCÍA, M.J. (1988): "Estudio del efecto de isla térmica de la ciudad de Valencia", en Coloquio hispano-francés sobre teledetección y planificación integrada del territorio, Madrid. 